\title{
Trend in temperature extreme indices over Mongolia and associated large-scale circulations
}

Baljinnyam Nyamjantsan ( $\nabla$ n.baljin@gmail.com )

Ewha Womans University https://orcid.org/0000-0002-4144-0059

Changhyun Yoo

Ewha Womans University

\section{Research Letter}

Keywords: TN10p, TX10p, TN90p, TX90p, human health, economy

Posted Date: December 23rd, 2020

DOl: https://doi.org/10.21203/rs.3.rs-133487/v1

License: (9) This work is licensed under a Creative Commons Attribution 4.0 International License. Read Full License 


\section{Abstract}

Employing the percentile-based indices, TN10p, TX10p, TN90p, and TX90p during 1961-2018, we evaluate temporal and spatial trends in extreme temperature at 54 stations over Mongolia. Statically significant changes in temperature extremes in the warm (TN90p and TX90p) and cool indices (TN10p and TX10p) are found. The rate of increase in the number of warm nights and days are respectively 1.5 and 1.9 days decade ${ }^{-1}$, while the cool nights and days show a declining trend of -0.8 and -1.5 days decade $^{-1}$, respectively. Despite the fact that the trends are most vigorous during June-July-August, seasonal variations can be seen. Also, spatial distributions of the trends reveal weakest magnitudes in Gobi Desert, while strongest in the west and north of Mongolia. The large-scale atmospheric circulations account for changes in the temperature extreme indices. The East Atlantic, East Atlantic/western Russian, and Scandinavian patterns, and the Arctic Oscillation is found to contribute the most to the interannual variation in the temperature extremes.

\section{Introduction}

Extreme temperature events are one of the most devastating natural disasters that has substantial impacts on human health, economy, and ecosystem (e.g., Vose et al., 2017, Wang et al., 2016, ). For example, the heat wave in the summer of 2010 over Russia was the strongest one in recent decades, and it contributed to deaths of over 15,000 people in Moscow and wildfires over central and western part of Russia (Russo et al., 2014). Another severe heatwave occurred in China the summer of 2013 during that event human, livestock and crops suffered from water shortage and companying drought resulted in economic losses approximately 10 million USD (Li et al., 2019). Understanding the long-term trend, variability, and the associated physical mechanisms of extreme temperature events is therefore of key importance. Objective quantification methods have been coordinated and developed by the Expert Team on Climate Change Detection and Indices (ETCCDI; see http://etccdi.pacificclimate.org/list_27_indices.shtml). The indices aim to capture variations of mean and extreme temperatures, as well as the shape of their statistical distributions.

With climate change showing rapid warming over mid-latitude central Asia (Lee et al., 2017;), studies have examined how temperature extremes have changed over Mongolia. Using observation from 25 stations over the period 1961-2001, Batima et al. (2005) revealed a significant increase in the annual number of heatwaves by 8-18 days. Regionally, the trend was stronger in the northern mountainous area than that in the southern Gobi Desert area. Later, a negative trend in cold extremes is also found in the northern region of Mongolia during the period 1963-2002, as well as the positive trend of hot extremes (Nandintsetseg et al., 2007). With recent observations included in the analyses, Dulamsuren et al (2014) detected that there is also variation in the trend within the analyzed period; a significant decrease in number of cool nights and days has taken place before 1990, while after 1996, an increase in the warm nights and days has occurred. In addition, the frequency of occurrence and duration of the hot extremes have sharply increased since the late 1990s. The changes in occurrence frequency and duration seem to 
be associated with middle tropospheric ridge pattern around Mongolia, indicating that synoptic-scale circulation has contributed to the recent increase in the heatwave days (Erdenebat et al, 2015).

Despite the trends detected over Mongolia, we do not fully understand yet how the changes vary by regions and seasons. More importantly, it is not addressed how the characteristics of the trend is linked to slowly varying, large-scale atmospheric circulation, which is a primary factor that determines physical processes, such as thermal advection and diabatic heating, causing long-term variability and changes in extreme temperature. It is locally different which mode of atmospheric variability accounts for the most of climate variability. For East Asia, which includes Mongolia, it was the East Atlantic/western Russian (EAWR), Scandinavian (SCAND), and polar/Eurasian (PE) teleconnection patterns among the seven major teleconnection patterns of the Northern Hemisphere, when measured by the prediction skill at subseasonal time scales (Yoo et al. 2018). Also, the Arctic Oscillation is the most dominant one for East Asian climate during winter (He et al. 2017).

The objective of this study is therefore to investigate the changes of temperature extremes in Mongolia and their associated large-scale atmospheric circulations. Building upon the previous studies that have analyzed the trend of Mongolia, here we expand the time period and perform regional and seasonal analyses. Then we will try to find linkages how the trend can be attributed to the large-scale atmospheric mode of variability. The study is organized as follows: the data and methodology are described in Sect. 2 . Section 3 presents the results of trend and correlation analyses for extreme temperature indices and large-scale atmospheric circulations. Conclusions and discussion are given in Sect. 4.

\section{Data And Methods \\ 2.1. Data}

We examine the daily maximum and minimum temperatures during the period of 1961 to 2018 from 54 meteorological stations maintained by the National Agency for Meteorology and Environmental Monitoring (NAMEM) of Mongolia. The geographical domain of Mongolia covers $43^{\circ}-52^{\circ} \mathrm{N}$ and $85^{\circ}-120^{\circ} \mathrm{E}$ with an area of about 1,564,116 square kilometers and elevations ranging between $560 \mathrm{~m}$ and 4,360 m above the sea level, and the stations are distributed throughout the country (Fig. S1). Note that there are 135 meteorological stations currently operational in Mongolia. However, the data from the rest 81 stations are not used primarily because of their lengths.

We also employ the monthly mean meteorological data from the European Centre for Medium-Range Weather Forecast (ECMWF) interim reanalysis (ERA-Interim) (Dee et al., 2011). The variables analyzed are the surface air temperature, geopotential height at $500 \mathrm{hPa}$, and zonal and meridional winds at $500 \mathrm{hPa}$. Before the analysis, the data is bilinearly interpolated to $2.5^{\circ}$ horizontal resolution.

To examine the linkage between the extreme temperatures of Mongolia and the large-scale atmospheric circulations, the atmospheric teleconnection pattern indices, defined by the Climate Prediction Center (CPC) of the National Oceanic and Atmospheric Administration (NOAA, website 
https://www.cpc.ncep.noaa.gov) are used. The teleconnection patterns that we examine are the ones dominant at $500 \mathrm{hPa}$ geopotential height field of the Northern Hemisphere: the Pacific North America (PNA), North Atlantic Oscillation (NAO), Scandinavia (SCAND), West Pacific (WP), Polar/Eurasia (PE), East Atlantic (EA), and East Atlantic/Western Russian (EAWR) (Fig. S2). Also, the Arctic Oscillation (AO), which is based on variability of column integrated atmospheric mass, is investigated. The time period of analysis is consistent with that of ERA-Interim.

\subsection{Method}

Percentile based extreme temperature indices are used in this study. The indices are computed using the ClimPact2 software, developed by the World Meteorological Organization ETCCDI, which calculates a set of core climate indices consisting of 27 descriptive indices for moderate extremes (Alexander et al., 2006; Zhang et al., 2011, Yosef et al., 2019). Out of total 27 indices, 11 indices are derived from air temperatures, and they can be divided into four different categories: absolute extreme temperature indices, percentile-based extreme temperature indices, duration-based and fixed threshold indices. The percentile based four indices are designed to capture the changes in the frequency of occurrence of statistical extremes (Table 1; see Alexander et al., 2006 for more details). To be specific, the TN10p is an index measuring the number of days with daily minimum temperature (i.e., TN) lower than the 10th percentile of the minimum temperature calculated each calendar day, with reference to the climatological norm, using a running 5-day window (Dulamsuren et al.,2014; Klein et al., 2006). This is the quantification of the number of unseasonably low temperature nights (i.e., cool nights) in a year. Similarly, the TX10p is an index trailing the number of unseasonably low-temperature days (cool days) by measuring the number of days with daily maximum temperature (i.e., TX) lower than the 10th percentile of the maximum temperature. In contrast, TN90p and TX90p are the indices corresponding to the number of unseasonably high-temperature nights (warm nights) and days (warm days) in a year, respectively. Both TN90p and TX90p are obtained by examining the days above the 90th percentile.

Table 1

Definition of percentile-based extreme temperature indices

\begin{tabular}{|llll|}
\hline Index & Indicator name & Description & Unit \\
\hline TN10p & Cool nights & Number of days with $\mathrm{TN}<10$ th percentile & Days \\
\hline TX10p & Cool days & Number of days with $\mathrm{TX}<10$ th percentile & Days \\
\hline TN90p & Warm nights & Number of days with $\mathrm{TN}>$ 90th percentile & Days \\
\hline TX90p & Warm days & Number of days with TX $>$ 90th percentile & Days \\
\hline
\end{tabular}

\section{Results}

To overview the nation-wide long-term trend and variability, we first examine the time series of annual mean and station mean percentile based extreme indices (Fig. 1). Note that the indices are originally computed for each month and each station. It can be clearly seen that the numbers of cool nights 
(TN10p; Fig. 1a) and cool days (TX10p; Fig. 1b) have decreased during 1961-2018, and the trend (blue lines) is arguably quite steady despite interannual variabilities (red curves). The rates of decrease for TN10p and TX10p are -1.5 days per decade and -0.8 days per decade, respectively, both of which exceed the $95 \%$ confidence level. In contrast, the number of warm nights (TN90p; Fig. 1c) and warm days (TX90p; Fig. 1d) shows the opposite, increasing trends, with significant rates of 1.9 and 1.5 days per decade, respectively. This nation-wide, annually averaged view suggests that extremely warm days (TX90p) have been more frequently occurrent in recent years than before, while at the same time, the occurrence of extremely cold nights (TN10p) has been declined (Fig. 1). Over the course of the analyzed time period, which is slightly less than 5 decades, the difference between the years in the beginning and at the end is approximately 5- to 10-days per year. This result is consistent with previous studies (Batima et al., 2005; Nandintsetseg et al., 2007; Dulamsuren et al.,2014; Dong et al., 2017), although exact values are not the same because of presumably the number stations and the period of data.

We note that the trends in the night indices (TN10p and TN90p) show similar magnitude to each other, while that from the day indices (TX10p and TX90p) are quite different. In other words, the absolute values of the slopes for the night indices are 0.15 and 0.19 , while those for the day indices are 0.08 and 0.15 . This implies that the probability distribution of minimum temperature has moved its center to the right without changing its shape much (not shown). However, for the maximum temperature, the right tail has been stretched out to the right faster than the speed of shrinking in its left tail, resulting in enhanced positive skewness of the data. This may also be hinted from the country averaged annual minimum of daily minimum temperature ( $T N n)$ and maximum of daily maximum temperature (TXX) (Fig. S3). The rate of increase in the $\mathrm{TNn}\left(0.33^{\circ} \mathrm{C}\right.$ per decade $)$ is greater than that of $\operatorname{TXx}\left(0.43^{\circ} \mathrm{C}\right.$ per decade).

We now examine spatial patterns in the trends of the percentile-based indices. In general, spatial homogeneity over Mongolia can be seen from all of the extreme indices. That is, the trends, either positive or negative depending on the indices, show almost uniform signs across Mongolia with a few exceptions. In particular, the TN10p (Fig. 2a) shows negative trend in all of the meteorological stations except three stations in the central part of the area. For the other three indices, one can see spatially homogeneous trends. That being said, small spatial variations can be seen between the stations. This is probably due to different regional climates. As described in the Supplementary Materials, Mongolia can be divided in to four different climate zones, which are characterized by the influence of the Altai and Khangai mountains, desert plains, and broad steppes area.

The spatial homogeneity in the trend patterns suggests that the trends can primarily be attributed to large-scale changes in the atmosphere and hence that the local effect can be considered as a secondary factor. Enhanced radiative heating by an increase in greenhouse gas concentration can be one factor (Chen et al., 2019). However, because the extreme temperature indices show substantial interannual variations in the order of approximately 5-10 days (Fig. 1), and the magnitude of their trends is comparable to the variation, it is natural to think that changes in large-scale atmospheric circulations, which involve dynamical processes, such as thermal advections, must be the primary factor that contributes to the trends. 
Having established that there is a nation-wide long-term trend in the temperature extreme indices over Mongolia, with the most pronounced trend being the increase in the number of warm nights and days (i.e., TN90p and TX90p), now we examine the seasonal variations in the trends. Figures S4 and S5 exhibit that the magnitude and spatial distributions of the temperature extremes have experienced significant changes by the seasons. One noticeable seasonality is perhaps the largest magnitude of the trends during June-July-August (JJA). When averaged for the entire country, the trends show values of -1.9 (TN10p), -1.4 (TX10p), 3.0 (TN90p), and 2.6 (TX90p) days per decade (Table 2). The trend values are smaller in the other seasons for all the indices, with the smallest values being found in DecemberJanuary-February (DJF).

Table 2

Linear trends of seasonal percentile-based temperature extremes over Mongolia during years 1961-2018. The units are days per decade.

\begin{tabular}{|lllll|}
\hline & Cool nights (TN10p) & $\begin{array}{l}\text { Cool days } \\
\text { (TX10p) }\end{array}$ & $\begin{array}{l}\text { Warm nights } \\
\text { (TN90p) }\end{array}$ & $\begin{array}{l}\text { Warm days } \\
\text { (TX90p) }\end{array}$ \\
\hline DJF & -1.6 & -0.5 & 0.9 & 0.2 \\
\hline MAM & -1.6 & -0.9 & 2.2 & 1.9 \\
\hline JJA & -1.9 & -1.4 & 3.0 & 2.6 \\
\hline SON & -1.2 & -0.6 & 1.4 & 0.9 \\
\hline
\end{tabular}

Although the trends are the strongest during JJA, the seasonal variations are different by the indices. The warm indices show greater changes in the trend values by the season than the cool indices do. For example, the difference between JJA and DJF trends is 2.25 days per decade for the warm indices, while the difference for the cold indices (-0.6 days per decade) is substantially small (Table 2 ). It is the cool nights index (TN10p) that performs the smallest changes by the season (-0.3 days per decade). This result indicates that the changes in the probability distribution of minimum and maximum temperatures show different characteristics by the season. From the annual mean values (i.e., Fig. 1), it was found that the maximum temperature experienced changes enhancing the positive skewness of its probability distribution. Now we further understand that the minimum temperature similarly shows changes in skewness for its probability distribution and that the changes are toward negative and positive values during DJF and JJA, respectively.

Spatial inhomogeneity can be magnified when the trend is examined by the season, although still more frequent warm extremes and less frequent cold extremes can be seen from most of the stations (Figs. S4 and S5). As mentioned earlier, Mongolia is divided into four natural regions (please see Fig. S1) based on land cover such as western high mountain climate, northern forest steppe climate, eastern steppe climate, and southern Gobi Desert. The trend is clearly weakest in the desert region; both cool and warm indices show the smallest values in all seasons. The largest trend values are located in the north and west of Mongolia. 
To investigate how large-scale atmospheric circulations have influenced the changes in the extreme temperature indices, we now perform the correlation analysis using 8 major atmospheric teleconnection pattern indices for the Northern Hemisphere (Fig. 3). Also, computed are the correlations between the extreme indices so that we can comprehend how the extreme indices linked to each other.

First about the relationship between the extreme indices, significantly high correlations can be seen between the cool indices and between the warm indices. That is, the TN10p and TX10p show positive and the TN90p and TX90p show negative correlations, which exceed the 95\% confidence level by the Student t-test for all seasons. Also can be seen is that the night indices (i.e., TN10p and TN90p) are negatively correlated with each other and similarly the day indices (i.e., TN90p and TX90p) are negatively correlated with each other. This is consistent with our previous finding that the cool extreme indices have exhibited significantly decreasing trends, while the warm extreme indices significantly increasing trends.

Secondly, among the 8 atmospheric teleconnections, the correlation matrix finds substantial relationship with the extreme indices of Mongolia from the following 4 patterns: EA, EAWR, SCAND, and AO (Fig. 3). Note that the correlation values less than the $95 \%$ confidence level are crossed out. One can see that it is the EA which carries good correlation with the extreme temperature indices for all seasons except autumn. Positive correlations can be seen between the EA and the warm indices (TN90p and TX90p), and negative correlations can be seen for the cool indices (TN10p and TX10p). The largest values for the EA can be seen during summer (Fig. 3c). This is interesting considering the fact that the explained variance by the large-scale circulations is the largest during winter. However, the result is consistent with our understanding because although located over the North Atlantic (Irannezhad et al., 2018), the EA can modulate temperatures over East Asia. Moreover, unlike the AO, which is dominant primarily during winter, the EA can be found as a major mode for all year around.

Other teleconnection patterns that show significant correlations with the temperature indices are the EAWR, SCAND, and AO. The three indices have circulation anomalies over Eurasia, stretching over Mongolia (Fig. S6). During the positive phase of the SCAND, the composite of the 500-hPa geopotential height anomalies exhibits a strong cyclonic circulation centered northern region over the East Asia, in particular over the part of western region in Mongolia. The same pattern with the opposite sign can be seen for the negative phase. For the positive (negative) phase of AO, positive (negative) geopotential anomalies are seen centered Baikal Lake on Siberia and northeastern region of Mongolia. Meanwhile, the mid-latitude and high latitude region including Mongolia is governed by warm (cold) and mild (dry) southerlies (northerlies). As for positive (negative) phase of EAWR are accompanied by strong Ural blocking around western Russian and Kazakhstan, while positive (negative) phase of EA is shown a weaker anticyclone (cyclone) centered over Mongolia.

The EAWR and SCAND are the wave-like patterns that emanates from the Europe and propagates to East Asia (Kim et al., 2021), while the $A O$ is a hemispheric mode with largest temperature anomalies over Eurasia. Previous studies have documented how the climate modes can modulate the temperature over East Asia (e.g., Park and Ahn 2016; Yoo et al. 2018). According to the correlation matrix, the winter 
correlations of TN10p and TX10p with the EAWR and AO indices are significantly negative, while they are positive for the SCAND index. This suggests the association of the EAWR and AO (SCAND) with anomalously warm (cold) condition over Mongolia. These were caused by penetration of cold from western Russian into Mongolia, which can be implied by the circulation anomalies (Fig. S6).

\section{Summary And Discussion}

In this study, we investigated the trends of percentile-based temperature extreme indices, their annual and seasonal variability using observations from 54 meteorological stations over Mongolia period during 1961 to 2018. We found that significantly warming trends are apparent in the warm indices (TN90p and TX90p), whereas gradually downward trends are seen in the cool indices (TN10p and TX10p). These findings suggest that the Mongolian climate generally tends to become warmer than before during the past 58 years. The warming trends seem to have been particularly accelerated since mid-1990 s, which is more alarming. The results reasonably agree well with the findings of previous studies (e.g., Dulamsuren et al., 2014; Erdenebat et al., 2016; Gomboluudev, 2011), even though there are differences between exact measures on the trend presumably due to chosen data period and analysis methods. In addition, we examined the seasonal trends of the temperature extremes. The warm indices dramatically changed during JJA about 2.9 and 3.4 days per decade, respectively. Throughout the period the cool indices showed moderately decreasing rates respectively at -2.0 and -1.4 days per decade particularly in the western and northern region of Mongolia.

The relationship between the large-scale atmospheric teleconnection patterns and extreme temperature indices are also investigated. It was found that EA, EAWR, SCAND, AO highly positively (negatively) correlated with both cool (warm) indices within study period. The characteristics of the seasonal correlation showed one notable results, which EA index and temperature extremes indices. EA pattern appears to be teleconnection most significantly associated with winter climate in East Asia, even though it found major mode all around year. Outcomes could be used for the analysis of the extremes in future scenarios

It remains as a question how changes in land use may have affected the temperature extremes. Changes in land cover is known to play an important role in the surface energy budget through radiation and turbulent heat fluxes, and therefore in regional climate (Chen et al., 2019; Wang et al., 2018). For instance, deforestation and land degradation can contribute to significant warming in the region by reducing albedo and latent heat flux. Because spatially the trends were most pronounced in the western high mountains and northern regions forest steppe of Mongolia, which occupies agricultural and biggest urbanization areas, regional effects, other than large-scale circulations, need further investigations.

\section{Declarations}

\section{Availability of data and material}


Not applicable'

\section{Competing interests}

'Not applicable'

\section{Funding}

'Not applicable'

\section{Authors' contributions}

'Not applicable'

\section{Acknowledgements}

This research was supported by the National Research Foundation of Korea (NRF) grant funded by Korea government (NRF-2018R1A6A1A08025520 and NRF-2019R1C1C1003161).

\section{Authors' information}

'Not applicable'

\section{References}

Alexander L. V, Zhang X, Peterson T C, Caesar J, Gleason B, Klein Tank AMG, Haylock M,

Collins, D Trewin B, Rahimzadeh F, Tagipour A, Rupa Kumar K, Revadekar J, Griffiths G, (2006) Global observed changes in daily climate extremes of temperature and precipitation. Journal of Geophysical Research 111(D5).

Batima P, N. L., Gombluudev P, Erdenetsetseg B (2005) Observed climate change in Mongolia. Assess Imp Adapt Clim Change Work Pap.12:1-26.

Broccoli, A. J. and P. C. Loikith (2012) Characteristics of Observed Atmospheric Circulation Patterns Associated with Temperature Extremes over North America. Journal of Climate 25(20): 7266-7281.

Chen W, Dong B (2019) Anthropogenic impacts on recent decadal change in temperature extremes over China: relative roles of greenhouse gases and anthropogenic aerosols". Clim Dyn 52, 3643-3660

Dashkhuu D, Kim J P, Chun J A, Lee W S (2015) Long-term trends in daily temperature extremes over Mongolia Weather and Climate Extremes 8: 26-33.

Dong S, Sun Y, Aguilar E, Zhang X, Peterson T C, Song (2017). Observed changes in temperature extremes over Asia and their attribution. Climate Dynamics 51(1-2): 339-353. 
Erdenebat E, T. Sato (2016) Recent increase in heat wave frequency around Mongolia: role of atmospheric forcing and possible influence of soil moisture deficit. Atmospheric Science Letters 17(2): 135-140.

Gomboluudev, P. (2011). High Resolution Projection of Climate Change and Climate Extremes (Drought/Zud) in Mongolia under the Increasing Green House Gas, Proceeding of conference

He S Y. Gao F Li, H Wang, Y He (2017) Impact of Arctic Oscillation on the East Asian climate: A review. Earth-Science Reviews, 164, 48-62

Herold, L. A. a. N. (2016). "ClimPACT2 Indices and software."

IPCC (2014) Climate Change 2014: synthesis report. In: Core Writing Team, P. R., Meyer LA (eds) (2014). Contribution of Working Group I, II and III to the fifth assessment report of the Intergovernmental Panel on Climate Change, IPCC, and Geneva

Irannezhad, M., et al. (2018) Spatiotemporal Variability and Trends in Extreme Temperature Events in Finland over the Recent Decades: Influence of Northern Hemisphere Teleconnection Patterns. Advances in Meteorology 2018: 1-17.

Kim M, C Yoo, M K Sung, and S Lee, 2021: Classification of wintertime atmospheric teleconnection patterns in the Northern Hemisphere. J. Climate, Online published

Klein Tank AM G, et al. (2006) Changes in daily temperature and precipitation extremes in central and south Asia. Journal of Geophysical Research 111(D16).

Lee M H, Lee S, Song H J, Ho C H (2017) The Recent Increase in the Occurrence of a Boreal Summer Teleconnection and Its Relationship with Temperature Extremes." Journal of Climate 30(18): 7493-7504.

Li, M., Yao Y, Luo D, Zhong L (2019). The Linkage of the Large-Scale Circulation Pattern to a Long-Lived Heatwave over Mideastern China in 2018. Atmosphere 10(2).

Lin H (2018) Predicting the Dominant Patterns of Subseasonal Variability of Wintertime Surface Air Temperature in Extratropical Northern Hemisphere. Geophysical Research Letters 45(9): 4381-4389.

MARCC. (2014) Dagvadorj, D., Batjargal, Z. and Natsagdorj, L (2014). Mongolia second assessment report on climate change 2014: 302.

Munkhjargal, E, Shinoda M, ljima Y (2020) Recently increased cold air outbreaks over Mongolia and their specific synoptic pattern. International Journal of Climatology 40(13): 5502-5514.

Nandintsetseg, B, Greene J, Clyde E G (2007) Trends in extreme daily precipitation and temperature near lake Hövsgöl, Mongolia. International Journal of Climatology 27(3): 341-347. 
Patteson Chula Mwagona , Y. Y., Yuanqi Shan , Hongxian Yu , and Yiwen Zhang (2018). "Trend and Abrupt Regime Shift of Temperature Extreme in Northeast China, 1957-2015." Hindawi Advances in Meteorology Volume 2018.

Shi, J, Cui L, Ma Y, Du H, Wen K (2018) Trends in temperature extremes and their association with circulation patterns in China during 1961-2015 Atmospheric Research 212: 259-272.

Unkašević M. and I. Tošić (2013) Trends in temperature indices over Serbia: relationships to large-scale circulation patterns. International Journal of Climatology 33(15): 3152-3161.

Vose R S, D. R. Easterling, K. E. Kunkel, A. N. LeGrande, and M. F. Wehner (2017) Temperature changes in the United States. Climate Science Special Report: Fourth National Climate Assessment, Volume I, D. J. Wuebbles, D. W. Fahey, K. A. Hibbard, D. J. Dokken, B. C. Stewart, and T. K. Maycock, Eds., U.S. Global Change Research Program, 185-206.

Wang X, Li Y, Chen Y, Lian J, Lou Y, Niu Y, Gong X, Yu P (2018) Temporal and spatial variation of extreme temperatures in an agro-pastoral ecotone of northern China from 1960 to 2016 . Sci Rep 8(1): 8787.

Yang Y, Xie N, Gao M (2019) The Relationship between the Wintertime Cold Extremes over East Asia with Large-Scale Atmospheric and Oceanic Teleconnections. Atmosphere 10(12).

Yosef Y, Aguilar E, Albert P (2019) Changes in extreme temperature and precipitation indices: Using an innovative daily homogenized database in Israel. International Journal of Climatology 39(13): 5022-5045.

\section{Figures}



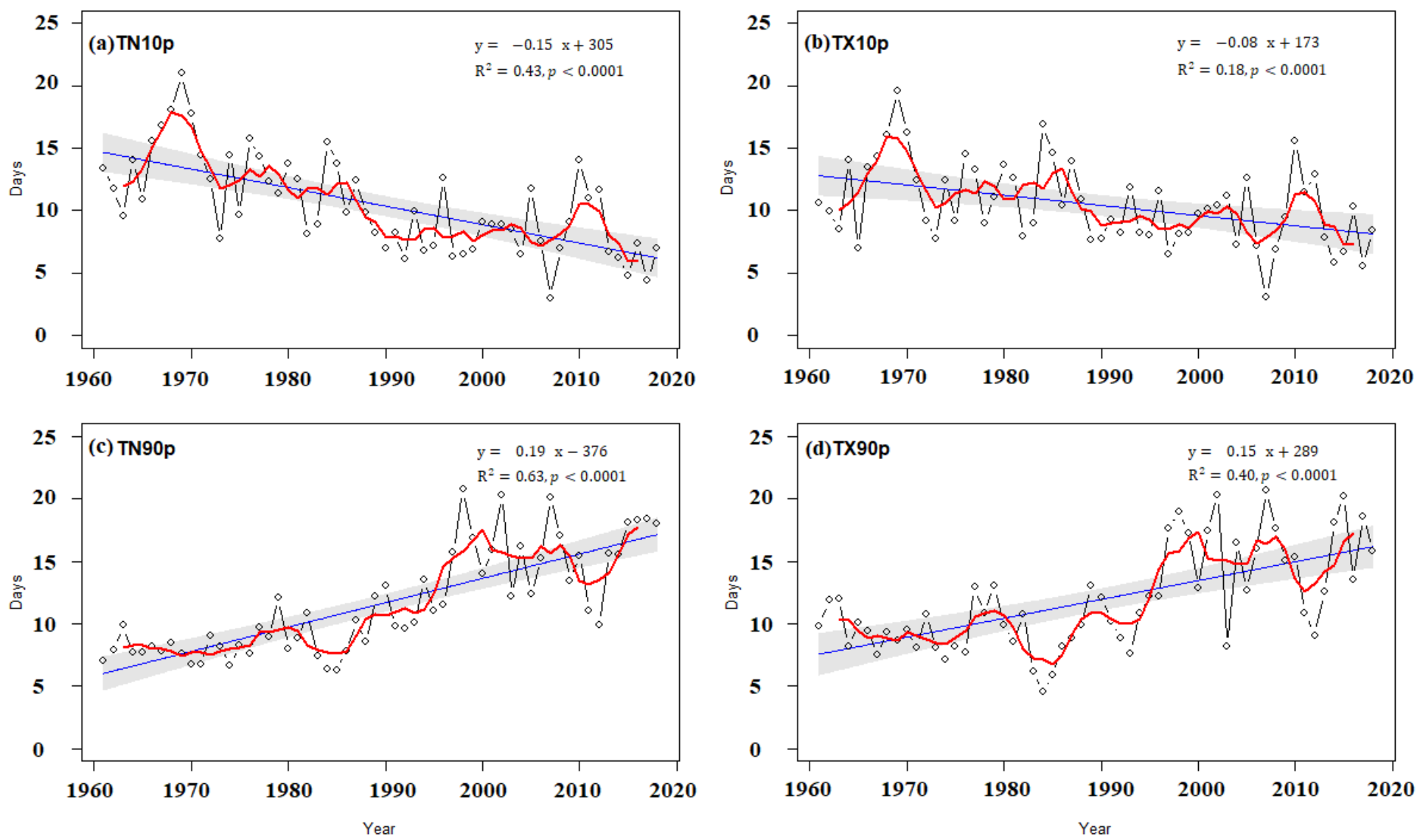

Figure 1

Percentile-based extreme temperature indices (black curve with open circle marks) are shown: (a) number of cool nights (TN10p), (b) number of cool days (TX10p), (c) number of warm nights (TN90p), and (d) number of warm days (TX90) averaged over all stations and seasons. Slow variations of the indices are presented by applying the 5-year running averages (red curve). Linear trend and the $95 \%$ confidence interval of the trend line are shown by blue line and gray shading, respectively 

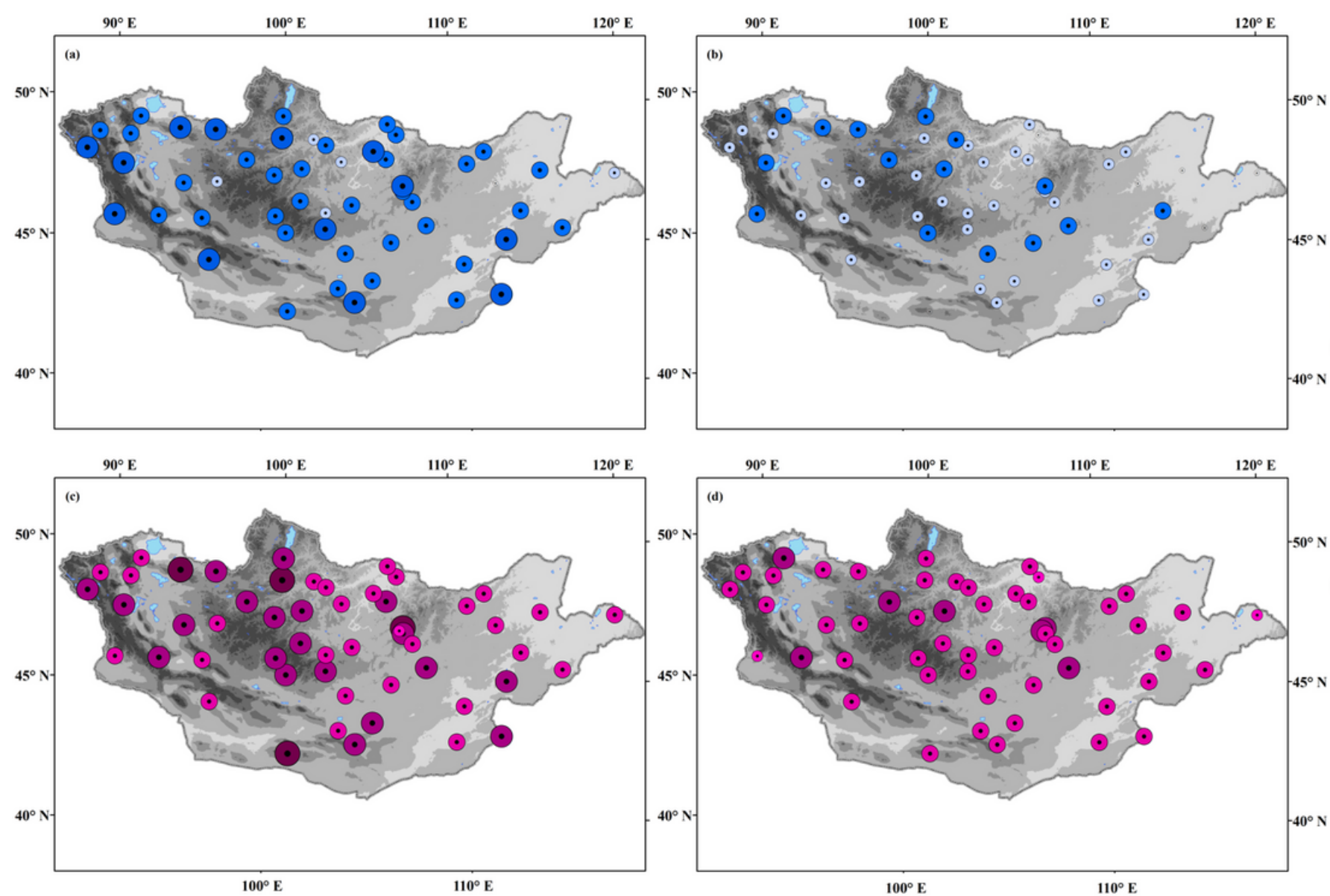

$90^{\circ} \mathbf{E}$

$100^{\circ} \mathrm{E}$

$110^{\circ} \mathrm{E}$

$120^{\circ} \mathrm{E}$

Days / Decade

- $<-3.0$

- $-3.0--2$

$-2.0--1.0$

(- $-1.0--0.5$

ค 0.0

- $0.5-1.00$

○ $1.0-2.0$

- $2.0-3.0$

- $>3.0$

\section{Figure 2}

Spatial distributions of the annual trends of the percentile-based extreme temperature indices are shown: (top left) cool nights (TN10p), (top right) cool days (TX10p), (bottom left) warm nights (TN90p), and (bottom right) warm days (TX90p), respectively. Labels Positive trend is shown by pink, while negative trend by blue. Most of the meteorological stations trends are at significance $(p<0.05)$. Note: The designations employed and the presentation of the material on this map do not imply the expression of any opinion whatsoever on the part of Research Square concerning the legal status of any country, territory, city or area or of its authorities, or concerning the delimitation of its frontiers or boundaries. This map has been provided by the authors. 

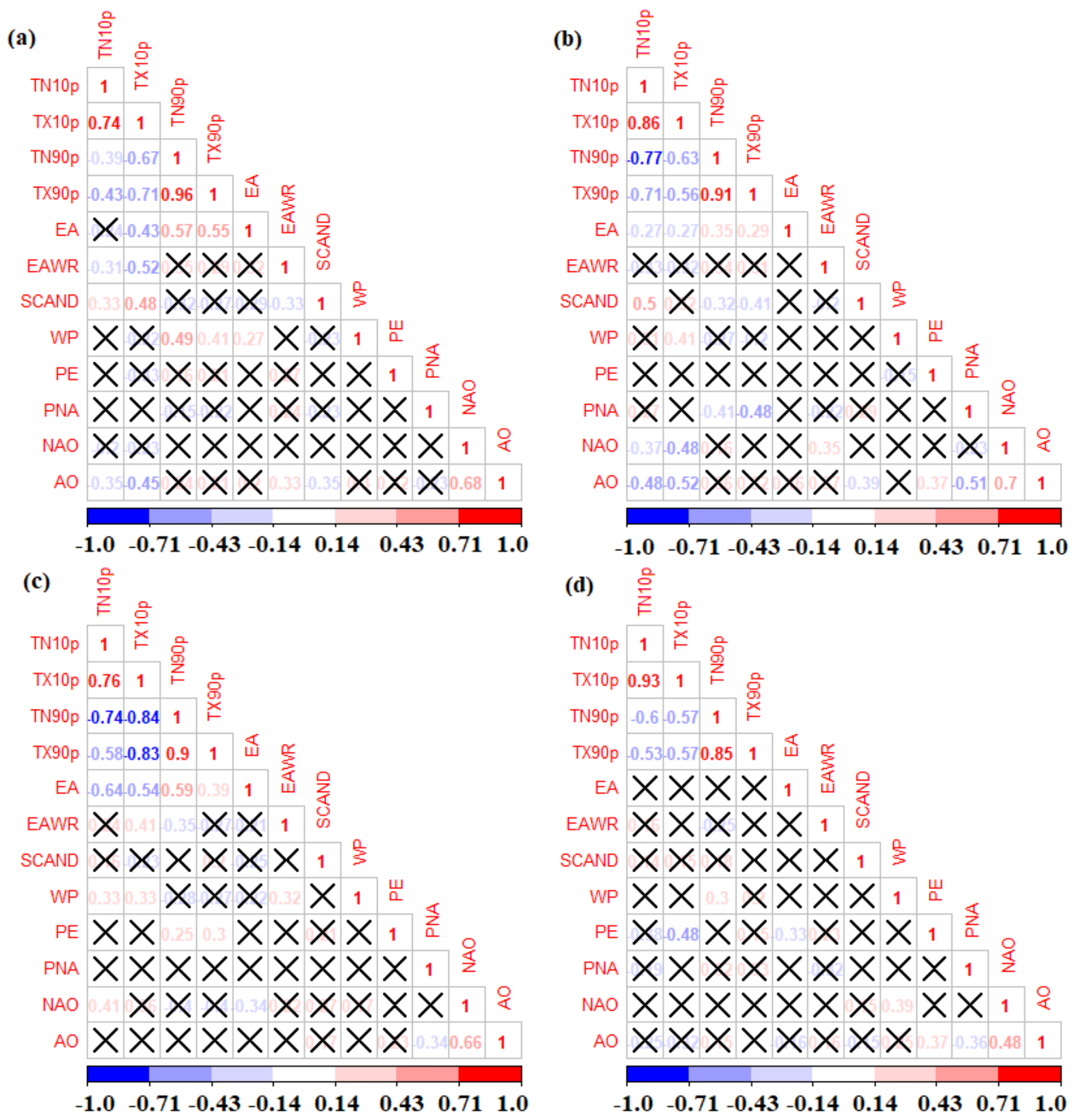

Figure 3

Correlation coefficients between the temperature extreme indices and teleconnection pattern indices in seasons of (a) DJF, (b) MAM, (c) JJA, and (d) SON. Positive values are shown in red, while negative values are in blue. The values that do not exceed the $95 \%$ confidence level are crossed out. 

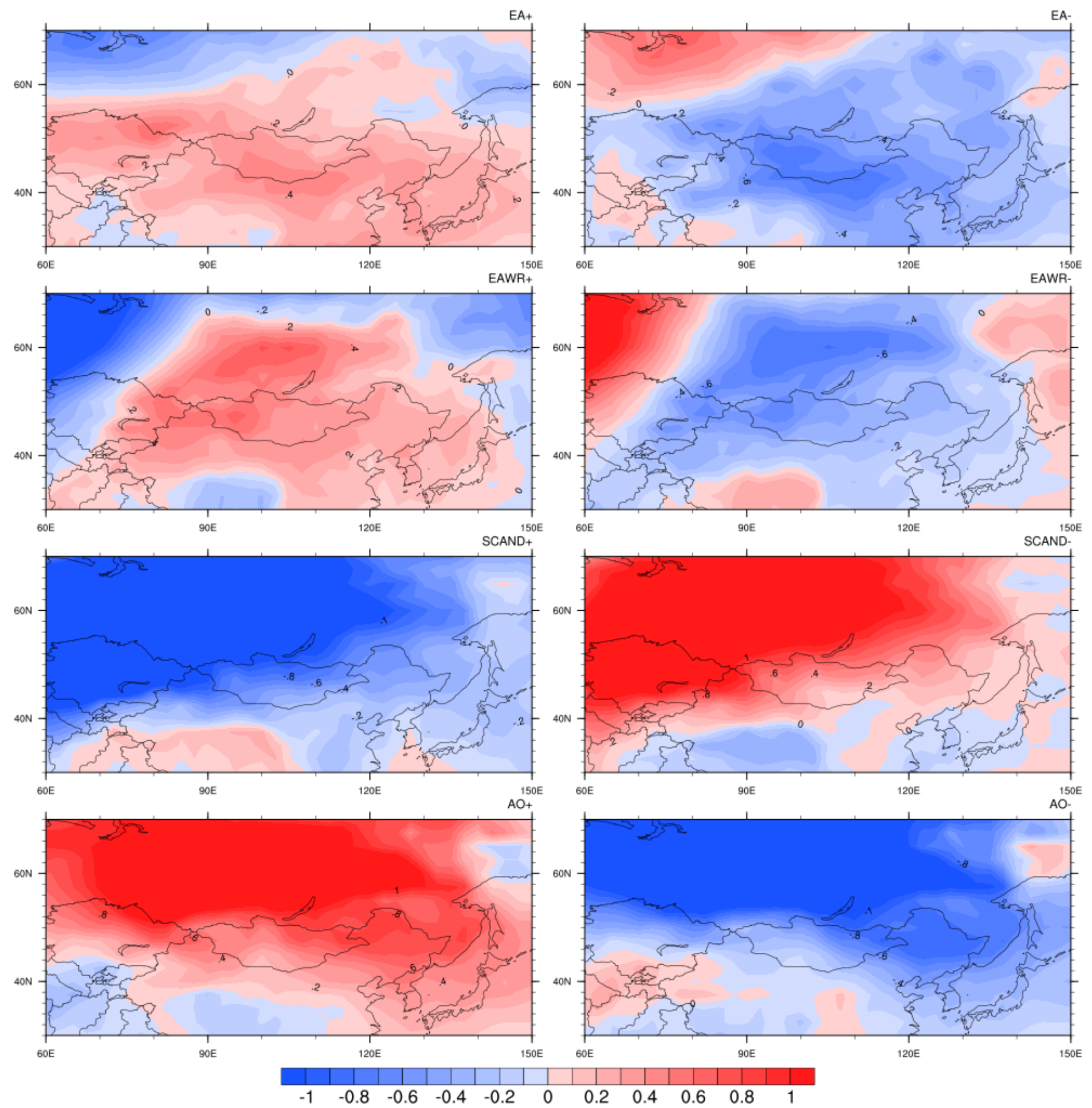

\section{Figure 4}

Composites of surface air temperature anomalies for (left) positive and (right) negative phases of (from the top to bottom) East Atlantic, East Atlantic Western Russia, Scandinavian teleconnection patterns and Arctic Oscillation. Note: The designations employed and the presentation of the material on this map do not imply the expression of any opinion whatsoever on the part of Research Square concerning the legal status of any country, territory, city or area or of its authorities, or concerning the delimitation of its frontiers or boundaries. This map has been provided by the authors. 


\section{Supplementary Files}

This is a list of supplementary files associated with this preprint. Click to download.

- Baljinnyamsupplementary.docx 